\title{
Genetic variants of NHEJ DNA ligase IV can affect the risk of developing multiple myeloma, a tumour characterised by aberrant class switch recombination
}

\author{
P L Roddam, S Rollinson, M O'Driscoll, P A Jeggo, A Jack, G J Morgan
}

See end of article for authors' affiliations

Correspondence to: Professor G J Morgan, Academic Unit of Haematology and Oncology, University of Leeds, Algernon Firth Building, Leeds, West Yorkshire LS2 9JT, UK; garethm@ pathology.leeds.ac.uk

Revised version received 20 August 2002 Accepted for publication 20 August 2002

\begin{abstract}
The DNA double stranded break (DSB) repair mechanism, non-homologous end joining (NHEJ) represents an essential step in antigen receptor gene rearrangement mechanisms, processes believed to be intimately involved in the aetiology of lymphoproliferative disease. We investigated the potential impact that previously undescribed polymorphisms identified within NHEJ DNA ligase IV (LIG4) have upon predisposition to several lymphoproliferative disorders, including leukaemia, lymphoma, and multiple myeloma. Two LIG4 polymorphisms were examined, both C>T transitions, which result in the amino acid substitutions A3V and T9I. Inheritance of the LIG4 A3V CT genotype was found to be significantly associated with a two-fold reduction in risk of developing multiple myeloma (OR 0.49, 95\% $\mathrm{Cl} 0.27$ to 0.89). Similarly, inheritance of the LIG4 T9I CT and the T9I TT genotypes were found to associate with a 1.5 -fold reduction (OR $0.77,95 \% \mathrm{Cl} 0.51$ to 1.17 ) and a four-fold reduction (OR $0.22,95 \% \mathrm{Cl} 0.07$ to 0.70 ) in risk of developing multiple myeloma respectively, suggesting a gene dosage effect for this polymorphism. The LIG4 A3V and T9I variant alleles are in linkage disequilibrium $\left(D^{\prime}=0.95, p<0.0001\right)$, and the protective effect associated with these polymorphisms was found to be the result of inheritance of the A3V-T9I CT and A3V-T9I TT haplotypes. These data suggest that genetic variants of NHEJ LIG4 may modulate predisposition to multiple myeloma, a tumour characterised by aberrant immunoglobulin (lg) class switch recombination.
\end{abstract}

A n effective immune response is dependent upon lymphocyte $\mathrm{B}$ cell and $\mathrm{T}$ cell antigen receptor diversity, generated by intrinsic gene rearrangement mechanisms including V(D)J recombination, somatic hypermutation, and Ig class switch recombination. Rare errors in these physiological processes can directly modify genomic DNA resulting in oncogene deregulation and subsequent malignant transformation. ${ }^{1}$ A central feature of both physiological antigen receptor rearrangement and aberrant rearrangement leading to chromosomal translocation is the generation and repair of DNA DSBs. The repair of DNA DSBs is accomplished predominantly by NHEJ, with contribution from homologous recombination (HR). ${ }^{23}$ Studies in rodents have suggested that the NHEJ repair mechanism is an integral step in both $\mathrm{V}(\mathrm{D}) \mathrm{J}$ recombination and Ig class switching. ${ }^{4-6}$ Grawunder $e t ~ a l^{7}$ reported that targeted disruption of the LIG4 gene, which functions in NHEJ, resulted in the abolition of $\mathrm{V}(\mathrm{D}) \mathrm{J}$ recombination in human precursor $\mathrm{B}$ cell lymphocytes. ${ }^{7}$ The mechanism of somatic hypermutation is likely to differ significantly from $\mathrm{V}(\mathrm{D}) \mathrm{J}$ recombination and switch recombination, with studies showing that NHEJ is not required. ${ }^{8}$

Components of the NHEJ pathway include the DNA-PK complex, consisting of a Ku70/Ku86 heterodimer and a large catalytic subunit called DNA-PK $\mathrm{P}_{\mathrm{cs}}$. The Ku heterodimer has a high affinity for non-specific double stranded DNA ends. Following binding, $\mathrm{Ku}$ recruits and interacts with DNA-PK $\mathrm{cs}^{\prime}$ stimulating its kinase activity. ${ }^{9}$ The final step of NHEJ repair involves the ligation of the DNA ends by the XRCC4/DNA ligase IV complex. ${ }^{10}$ Mice deficient in any of the NHEJ genes show immunodeficiency and radiosensitivity. Recent studies have shown mouse embryonic fibroblasts lacking $K u 70, K u 86$, $D N A-P K_{c s}, X r c c 4$, or Lig4 activity exhibit significant genomic instability ${ }^{11-13}$ Furthermore, mice deficient in $D N A-P K_{c^{\prime}}, K u 86$, or Xrcc4, plus the tumour suppressor gene TP53, were found to develop B cell lymphoma within months of birth, suggesting that a p53 dependent pathway may prevent proliferation of genetically altered cells arising through defective NHEJ. The tumours resembled human lymphoid tumours characterised by chromosomal translocations into the IgH region, deregulating $c$-myc. ${ }^{14}{ }^{15} \mathrm{An}$ increased risk of lymphoma, typically involving translocations involving the antigen receptor loci, ${ }^{16}$ is also observed in ataxia-telangiectasia and Nijmegen breakage syndrome, two syndromes associated with aberrant responses to DNA DSBs. Additionally, a mutation in LIG4 was detected in a leukaemia patient (patient 180BR) who dramatically over-responded to radiotherapy. ${ }^{17}$ Taken together, these studies suggest that aberrant processing of DNA DSBs and aberrant functioning of NHEJ in particular may be an important factor in the aetiology of lymphoid malignancy.

Recently, O'Driscoll et al ${ }^{18}$ identified further patients with mutations in LIG4. These patients, classified as LIGIV syndrome patients, displayed immunodeficiency and growth and developmental delay but, to date, tumours have not been found in the small number of patients reported. Cell lines derived from these patients exhibit radiosensitivity and defective DNA DSB repair, plus an impaired ability to carry out $\mathrm{V}(\mathrm{D}) \mathrm{J}$ recombination. The original leukaemia patient (patient 180BR) was developmentally normal with no overt immunodeficiency, but had the same homozygous germline mutation $(\mathrm{R} 278 \mathrm{H})$ as that found in one of the more severely affected LIGIV syndrome patients (patient 4l1BR). Patient $41 \mathrm{lBR}$ was found, in addition to the R278H mutation, to be a double homozygote variant for two N-terminal polymorphisms, both $\mathrm{C}>\mathrm{T}$ transitions, at nucleotide positions 8 and 26, resulting in the amino acid substitutions A3V and T9I, respectively. Although neither polymorphism is thought to alter significantly the structural conformation of the DNA ligase IV protein, collectively they are predicted to increase the hydrophobicity of that region. ${ }^{18}$ The NCBI accession number for LIG4 is NM_002312, although the correct protein 

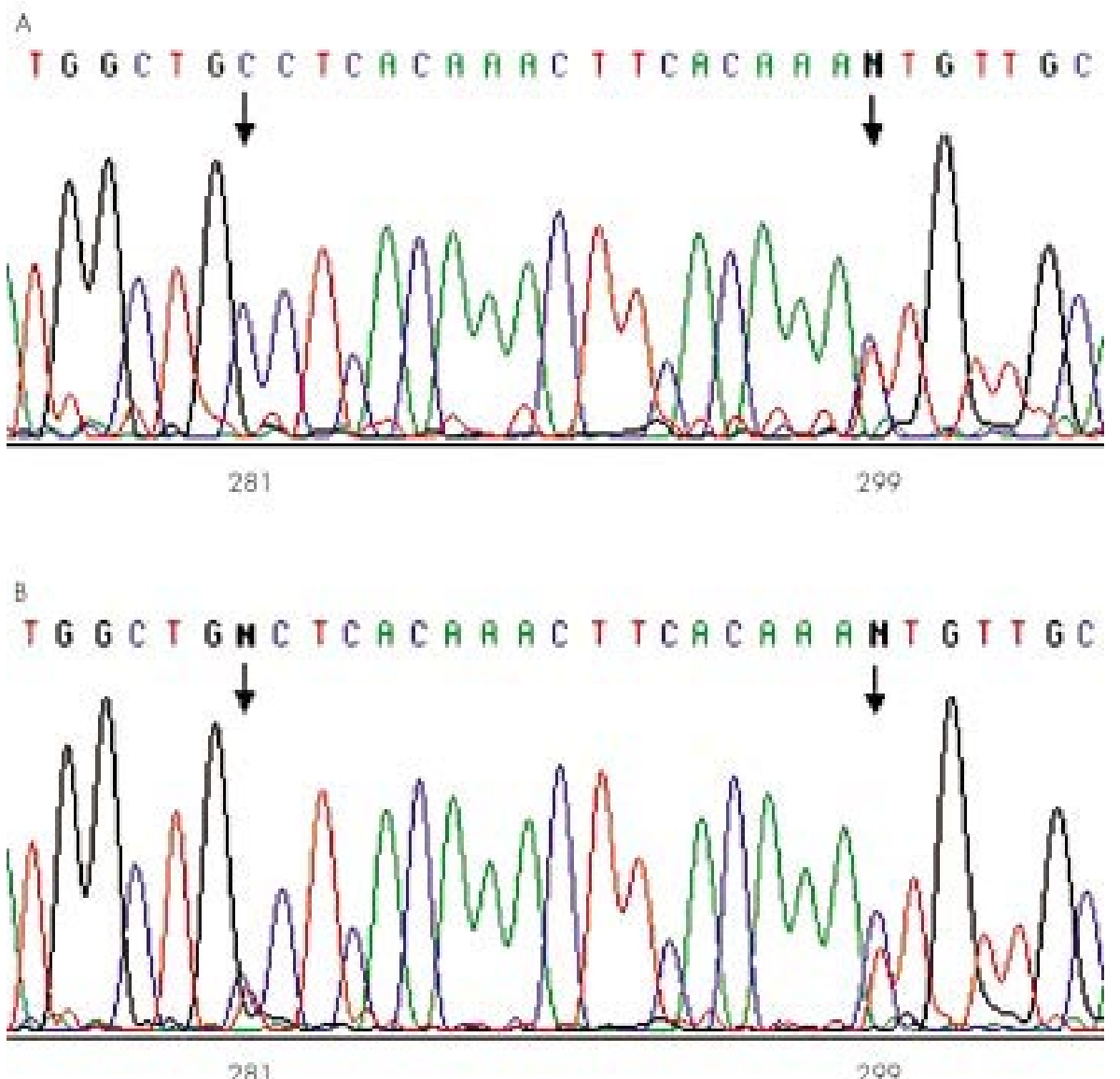

Figure 1 Examples of DNA sequence data used to validate LIG4 Taqman ${ }^{\text {TM }}$ Allelic Discrimination assays. Electropherograms span both LIG4 variant sites, showing alleles at mRNA nucleotide positions 281 and 299 correlating with polymorphisms A3V and T9I, respectively. Sequence A shows combined LIG4 A3V CC (wild type) and T9I CT (heterozygote) genotype. Sequence B shows combined LIG4 A3V CT (heterozygote) and T9I CT (heterozygote) genotype.

coding sequence begins with an earlier ATG at position 274. This differs from that described in NM_002312; however, this region has been shown to be essential for DNA ligase IV activity, ${ }^{19}$ raising the possibility that the A3V and T9I polymorphisms might confer some impact on DNA ligase IV function. We therefore examined the impact of these genetic variants in the aetiology of lymphoproliferative disease using the REAL categories ${ }^{20}$ : adult acute lymphoblastic leukaemia (ALL), follicular lymphoma (FCL), diffuse large B cell lymphoma (DLBCL), and multiple myeloma, the pathogenesis of which involve different contributions of the various antigen receptor rearrangement mechanisms. ${ }^{21}$

\section{METHODS}

\section{Study population}

Potential associations between LIG4 polymorphism and lymphoproliferative disease were investigated by Taqman ${ }^{\mathrm{TM}}$ Allelic Discrimination using a case-control approach. The study population was composed of archived tumour material, and of material collected by the Leukaemia Research Fund and the Myeloma VII population based case-control epidemiological studies. All case and controls were of European origin and for ALL, lymphoma, and multiple myeloma cases, all diagnoses were pathologically confirmed. Ethical approval was obtained for epidemiological study subjects. Control subjects used as the reference group were randomly chosen from a large population based lymphoma case-control study undertaken by the Leukaemia Research Fund. Genomic DNA was prepared for 220 controls, 364 lymphoma cases composed of 180 FCL cases and 184 DLBCL cases, 70 ALL cases, and 270 multiple myeloma cases using a standard laboratory protocol. $^{22}$

\section{LIG4 genotyping}

LIG4 A3V and T9I genotypes were determined using the ABI PRISM 7700 sequence detection system, with assay primers and probes designed by Primer Express ${ }^{\mathrm{TM}} \mathrm{v}$ 1.5. The A3V assay was undertaken using $900 \mathrm{nmol} / \mathrm{l}$ of both sense (5'TTGCTTTACTAGTTAAACGAGAAGATTCA-3') and antisense (degenerative) (5'-AACGTGAGATGCAACA(GA)TTTGTG-3') primers, $200 \mathrm{nmol} / \mathrm{l}$ of FAM labelled $\mathrm{C}$ allele probe (5'ACCGCTTTGATGGCTGCCTCACA-3'), and $100 \mathrm{nmol} / \mathrm{l}$ of VIC labelled $\mathrm{T}$ allele probe (5'-ACCGCTTTGATGGCTGTCTCACA$\left.3^{\prime}\right)$, with an annealing temperature of $63^{\circ} \mathrm{C}$. The T9I assay was undertaken using $900 \mathrm{nmol} / \mathrm{l}$ of both sense (5'GAGAAGATTCATCACCGCTTTGA-3') and antisense (5'TTCGTTCTAAAGTTGAACACAAATCTG-3') primers, and 100 nmol/l of both FAM labelled $C$ allele probe (5'ACAAACTTCACAAACTGTTGCATCTCACGTT-3') and VIC labelled $\mathrm{T}$ allele probe (5'-ACAAACTTCACAAATTGTTGC ATCTCACGTT-3'), with an annealing temperature of $66^{\circ} \mathrm{C}$. PCR reactions were carried out using 20-50 ng of DNA and IX Taqman $^{\mathrm{TM}}$ Universal PCR Master Mix, in a total volume of $20 \mu \mathrm{l}$. LIG4 A3V and T9I wild type (CC), heterozygote (CT), and homozygote variant (TT) genotype controls, plus nontemplate controls, were included within each plate. As a quality control measure, $10 \%$ of the control population were 
Table 1 Ligase IV A3V and T9I genotype distributions of controls and lymphoproliferative disorder cases, with odds ratios (OR) and $95 \%$ confidence intervals $(95 \% \mathrm{Cl})$

\begin{tabular}{|c|c|c|c|c|c|c|c|c|c|c|}
\hline \multirow[b]{2}{*}{ Ligase IV } & \multirow{2}{*}{ 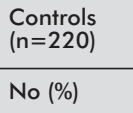 } & \multicolumn{3}{|l|}{ ALL $(n=70)$} & \multicolumn{3}{|c|}{ Lymphoma $(n=364)$} & \multicolumn{3}{|c|}{ Multiple myeloma $(n=270)$} \\
\hline & & No (\%) & OR* & $95 \% \mathrm{Cl}$ & No (\%) & $\mathrm{OR}^{*}$ & $95 \% \mathrm{Cl}$ & No. (\%) & $\mathrm{OR}^{*}$ & $95 \% \mathrm{Cl}$ \\
\hline \multicolumn{11}{|l|}{$\mathrm{A} 3 \mathrm{~V} \dagger$} \\
\hline CC & $189(85.9)$ & $61(87.1)$ & 1 & - & $316(86.8)$ & 1 & - & $247(91.5)$ & 1 & - \\
\hline $\mathrm{CT}$ & $31(14.1)$ & $9(12.9)$ & 0.90 & 0.41 to 2.00 & $48(13.2)$ & 0.93 & 0.57 to 1.51 & $20(7.4)$ & 0.49 & 0.27 to 0.89 \\
\hline$\pi$ & $0(0.0)$ & $0(0.0)$ & - & - & $0(0.0)$ & - & - & $1(0.4)$ & - & - \\
\hline SNA & - & - & & & - & & & 2 & & \\
\hline \multicolumn{11}{|l|}{ T91† } \\
\hline CC & $149(67.7)$ & $49(70.0)$ & 1 & - & $247(67.9)$ & 1 & - & $204(75.6)$ & 1 & - \\
\hline CT & $58(26.4)$ & $21(30.0)$ & 1.10 & 0.61 to 2.00 & $108(29.7)$ & 1.12 & 0.77 to 1.64 & $61(22.6)$ & 0.77 & 0.51 to 1.17 \\
\hline$\pi$ & $13(5.9)$ & $0(0.0)$ & - & - & $7(1.9)$ & 0.32 & 0.13 to 0.83 & $4(1.5)$ & 0.22 & 0.07 to 0.70 \\
\hline SNA & - & - & & & 2 & & & 1 & & \\
\hline
\end{tabular}

randomly selected and genotyped for the $\mathrm{A} 3 \mathrm{~V}$ and $\mathrm{T} 9 \mathrm{I}$ polymorphisms a second time by direct sequencing (BigDye Terminator Kit, Applied Biosystems) (fig 1).

\section{Statistical analysis}

Odds ratios (OR) and 95\% confidence intervals (95\% CI) were estimated using logistic regression, conducted by Stata (Intercooled Stata 6.0 for Windows NT, Stata Corporation, 1999). Each disease group was analysed as an independent case series using the control group as a reference population where, with the exception of ALL (a relatively rare disease), analysis had approximately $80 \%$ power to detect an OR of 0.5 with a $95 \%$ confidence interval as determined by Epi Info v5.01a. Hardy-Weinberg equilibrium was tested by $\chi^{2}$ analysis for LIG4 genotype using the HWE software program (Linkage Utility Programs, Rockefeller University, USA). Haplotype frequency variation was assessed by $\chi^{2}$ analysis using the Astute for Excel package, plus the Yates correction for small numbers.

\section{Linkage analysis}

Investigation into possible linkage disequilibrium between LIG4 A3V and T9I polymorphisms took two forms: statistical prediction using linkage analysis software, EH and 2LD (Linkage Utility Programs, Rockefeller University, USA), and direct experimental analysis through A3V and T9I double heterozygote sequencing. EH was used to estimate LIG4 A3V-T9I haplotype frequency, followed by subsequent association analysis using $2 \mathrm{LD}$, to obtain a linkage disequilibrium $\mathrm{D}^{\prime}$ coefficient for the LIG4 variant alleles. Five control subjects identified with the A3V T9I double heterozygote genotype were cloned using the pGEM ${ }^{\circledR}$-T Easy Vector System (Promega), according to the manufacturer's instructions, and subsequently analysed by direct sequencing (BigDye Terminator Kit, Applied Biosystems).

\section{RESULTS}

The LIG4 A3V and T9I allele frequencies in the control population were 0.07 and 0.19 , respectively. The distribution of the A3V heterozygote genotype was similar in the control, ALL, and lymphoma case groups (table 1). A3V TT homozygous variants were not observed in either control or case series. The T9I heterozygote genotype distribution was also similar between case and control populations. However, the T9I TT genotype was found to be significantly under-represented within the ALL and lymphoma cases (table 1), suggesting that this genotype may protect against developing these disorders. This association was also seen following stratification of the lymphomas into FCL, tumours characterised by the $t(14 ; 18)$ abnormality $^{23}$ (OR 0.36, 95\% CI 0.12 to 1.14 ), and DLBCL (OR
$0.28,95 \%$ CI 0.08 to 1.02 ) (data not shown). Strikingly, the distribution of both A3V and T9I genotypes differed significantly for the multiple myeloma case population compared to controls (table 1), whereby significantly fewer multiple myeloma cases were heterozygous for the A3V allele, and a gene dosage effect was observed for the T9I allele. Thus, inheritance of a single copy of either A3V or T9I allele confers a 1.5 -fold reduction in risk of developing multiple myeloma, and inheritance of two copies of the T9I variant allele confers a four-fold reduction in risk of developing multiple myeloma (table 1). Examination of combined A3V and T9I genotype showed no interaction between them, either within the ALL or lymphoma case series (table 2). However, a significant interaction $\left(\chi^{2}=12.6, \mathrm{p}<0.05\right)$ was observed among multiple myeloma cases, with $50 \%$ fewer multiple myeloma cases genotyped as A3V T9I double heterozygotes compared to controls (table 2).

Distribution of the LIG4 A3V and T9I polymorphisms within the control population were investigated for HardyWeinberg equilibrium. The T9I genotype distribution was found to deviate significantly from equilibrium $\left(\chi^{2}=4.73\right.$, $\mathrm{p}=0.30$ ), with positive selection bias upon the T9I TT genotype. In contrast, distribution of the A3V genotype did not significantly deviate from Hardy-Weinberg equilibrium. However, the distribution of combined A3V T9I genotypes indicated strong linkage disequilibrium between the LIG4 polymorphisms. Statistical analysis using $\mathrm{EH}$ and 2LD predicted non-random association between the two variant alleles $\left(D^{\prime}=0.95, \chi^{2}=128.8, p<0.0001\right)$. Furthermore, direct experimental analysis, whereby five control subjects genotyped as double heterozygotes for A3V and T9I were cloned and sequenced, supported this statistical prediction of linkage disequilibrium as all A3V T9I double heterozygotes were found to possess the A3V and T9I C $>$ T base substitution in cis, not trans (data not shown). Therefore, subjects genotyped as double heterozygotes possess the two LIG4 haplotypes A3V-T9I CC and A3V-T9I TT. The apparent absence of selective pressure observed for the A3V genotype may be the result of the small number of controls used in this study and the relative rarity of the A3V variant allele in comparison with the T9I variant allele. Alternatively, the protective effect of the $\mathrm{A} 3 \mathrm{~V}$ polymorphism may arise as a consequence of association with the actual protective allele, T9I.

The combined LIG4 A3V T9I genotype distribution suggests that the T9I C $>$ T base substitution occurred first, producing the A3V-T9I CT haplotype, followed by a second event, the A3V $\mathrm{C}>\mathrm{T}$ substitution, on the same DNA strand producing the A3V-T9I TT haplotype. The rare A3V-T9I TC haplotype observed either resulted from limited recombination owing to the spatial proximity of the two alleles, or from an $\mathrm{A} 3 \mathrm{~V} \mathrm{C}>\mathrm{T}$ 
Table 2 Combined ligase IV A3V and T9I genotype distribution of controls and lymphoproliferative disorder cases, with odds ratios (OR) and $95 \%$ confidence intervals $(95 \% \mathrm{CI})$

\begin{tabular}{|c|c|c|c|c|c|c|c|c|c|c|c|}
\hline \multicolumn{2}{|c|}{$\begin{array}{l}\text { Ligase IV } \\
\text { polymorphism }\end{array}$} & \multirow{2}{*}{$\begin{array}{l}\text { Controls } \\
(n=220)\end{array}$} & \multicolumn{3}{|c|}{$\operatorname{ALL}(n=70)$} & \multicolumn{3}{|c|}{ Lymphoma $(n=364)$} & \multicolumn{3}{|c|}{ Multiple myeloma $(n=270)$} \\
\hline $\mathrm{A} 3 \mathrm{~V} \dagger$ & T91† & & No (\%) & OR* & $95 \% \mathrm{Cl}$ & No (\%) & OR* & $95 \% \mathrm{Cl}$ & No (\%) & OR* & $95 \% \mathrm{Cl}$ \\
\hline $\mathrm{CC}$ & $\mathrm{CC}$ & $148(67.3)$ & 49 (70.0) & 1 & - & 244 (67.0) & 1 & - & $202(74.8)$ & 1 & - \\
\hline $\mathrm{CC}$ & $\mathrm{CT}$ & $34(15.5)$ & $12(17.1)$ & 1.07 & 0.51 to 2.22 & $67(18.4)$ & 1.20 & 0.75 to 1.89 & $42(15.6)$ & 0.91 & 0.55 to 1.49 \\
\hline $\mathrm{CC}$ & $T T$ & $7(3.2)$ & $0(0.0)$ & - & - & $4(1.1)$ & 0.35 & 0.10 to 1.20 & $2(0.7)$ & 0.21 & 0.04 to 1.02 \\
\hline $\mathrm{CT}$ & $\mathrm{CC}$ & $1(0.5)$ & $0(0.0)$ & - & - & $3(0.8)$ & 1.82 & 0.19 to 17.66 & $1(0.4)$ & 0.73 & 0.05 to 11.81 \\
\hline $\mathrm{CT}$ & $\mathrm{CT}$ & 24 (10.9) & 9 (12.9) & 1.13 & 0.49 to 2.60 & 41 (11.3) & 1.04 & 0.60 to 1.78 & $18(6.7)$ & 0.55 & 0.29 to 1.05 \\
\hline $\mathrm{CT}$ & $\mathrm{TT}$ & $6(2.7)$ & $0(0.0)$ & - & - & $3(0.8)$ & 0.30 & 0.07 to 1.23 & $1(0.4)$ & 0.12 & 0.01 to 1.03 \\
\hline $\mathrm{TT}$ & $\mathrm{CC}$ & $0(0.0)$ & $0(0.0)$ & - & - & $0(0.0)$ & - & - & $0(0.0)$ & - & - \\
\hline TT & $\mathrm{CT}$ & $0(0.0)$ & $0(0.0)$ & - & - & $0(0.0)$ & - & - & $0(0.0)$ & - & - \\
\hline TT & $\mathrm{TT}$ & $0(0.0)$ & $0(0.0)$ & - & - & $0(0.0)$ & - & - & $1(0.4)$ & - & - \\
\hline SNA $\ddagger$ & & - & - & & & 2 & & & 3 & & \\
\hline
\end{tabular}

Table 3 Ligase IV A3V-T9I haplotype frequency distribution of controls and lymphoproliferative disorder cases

\begin{tabular}{|c|c|c|c|c|c|}
\hline \multicolumn{2}{|l|}{ Ligase IV } & \multicolumn{4}{|c|}{ Haplotype frequency* } \\
\hline A3V locus & T91 locus & Controls & ALL & Lymphoma & Myeloma \\
\hline C & C & 0.81 & 0.85 & 0.83 & 0.87 \\
\hline C & $\mathrm{T}$ & 0.12 & 0.09 & 0.11 & 0.09 \\
\hline $\mathrm{T}$ & C & 0.00 & 0.00 & 0.00 & 0.00 \\
\hline \multirow[t]{2}{*}{$\mathrm{T}$} & $\mathrm{T}$ & 0.07 & 0.06 & 0.06 & 0.04 \\
\hline & $p=\dagger$ & & $1.86,0.60$ & $1.20,0.75$ & $7.83,0.05$ \\
\hline
\end{tabular}

substitution occurring independently from the T9I mutation. No significant difference in haplotype frequencies was observed between the control population, and either the ALL or lymphoma case populations (table 3). However, LIG4 haplotype frequencies for the multiple myeloma cases differed significantly from those of the control population (table 3) $\left(\chi^{2}=7.83, p=0.05\right)$, suggesting that both the A3V-T9I CT and A3V-T9I TT haplotypes are associated with protection against the development of multiple myeloma. These data reflect the genotype analysis, whereby inheritance of a single copy of either the A3V or T9I variant alleles, independently or in combination, or inheritance of two copies of the T9I variant allele is associated with a significant reduction in risk of multiple myeloma. A similar association was not observed for inheritance of two copies of the A3V allele, possibly owing to the rarity of the A3V-T9I TC haplotype or the observed linkage disequilibrium between the A3V and T9I alleles.

\section{DISCUSSION}

Our data provide evidence to implicate germline variation within the NHEJ pathway in the risk of developing lymphoproliferative disease. We examined several lymphoproliferative disorder case series, ALL, FCL, DLBCL, and multiple myeloma, recognised by the REAL classification as distinct pathological entities, with potentially different aetiological mechanisms. ALL is a precursor cell disorder, originating from an early bone marrow progenitor which is in the process of $\mathrm{V}(\mathrm{D}) \mathrm{J}$ recombination. ${ }^{24}$ The germinal centre lymphomas analysed in this study, made up of both FCL and DLBCL cases, may have arisen through aberrant $\mathrm{V}(\mathrm{D}) \mathrm{J}$ recombination or receptor editing, possibly with contribution from somatic hypermutation and, in some instances, class switch recombination. ${ }^{25-27}$ In particular, the FCL group is characterised by $\mathrm{t}(14 ; 18)$, where $B C L 2$ is translocated from $18 \mathrm{q} 32$ into the $\mathrm{J}_{\mathrm{H}}$ region of the $\mathrm{Ig}$ heavy chain $(I G H)$ gene, with subsequent deregulation of the $B C L 2$ gene. ${ }^{23}$ In contrast, multiple myeloma is a malignant disorder of plasma cells characterised, in $60 \%$ of cases, by aberrant class switch recombination. $^{28}$ NHEJ and DNA ligation by LIG4 is important in all of these mechanisms of antigen receptor rearrangement. Our data show a protective effect associated with inheritance of the LIG4 A3V-T9I CT and TT haplotypes, suggesting that functional variation of NHEJ as a consequence of LIG4 polymorphism, can modulate the risk of lymphoproliferative disease. The risk is, however, most significant for multiple myeloma, a tumour associated with abnormal class switch recombination as an early pathogenetic event. The variation in effect observed for LIG4 $\mathrm{A} 3 \mathrm{~V}$ and T9I for the different lymphoproliferative disease groups could be attributed to the different DNA DSB repair mechanisms, essential for effective immunological response, used by the respective target for transformation. The various antigen receptor rearrangement processes may involve different components of repair pathways, as has been recently shown by studies in rodents investigating the role of mismatch repair proteins in somatic hypermutation and class switch recombination. ${ }^{29}$ Therefore, although Ig class switching and somatic hypermutation share a number of features suggesting common machinery, ${ }^{30}$ they are distinct mechanisms with specific components, including those involved in DNA repair as shown by the requirement for functional NHEJ in class switch recombination, but not somatic hypermutation. ${ }^{468}$

The LIG4 A3V and T9I polymorphisms were initially identified in a LIGIV syndrome patient (411BR), suggesting a deleterious impact of the polymorphisms upon DNA ligase IV function. Yet these data provide evidence to suggest the LIG4 $\mathrm{A} 3 \mathrm{~V}$ and T9I polymorphisms are protective in nature, conferring a reduced risk of developing multiple myeloma. Further support is provided by the apparent positive selection upon the T9I variant allele within the control population, suggesting that these LIG4 genetic variants may possess a protective role 
for other diseases in which defective DNA DSB repair is implicated as causative. It could be postulated that this observation of the LIG4 A3V and T9I polymorphisms results from the ubiquitous nature of DNA ligase IV and the NHEJ pathway, and its involvement in both $\mathrm{V}(\mathrm{D}) \mathrm{J}$ recombination and Ig class switch recombination. LIGIV syndrome patients show immunodeficiency through a reduced ability to undergo $\mathrm{V}(\mathrm{D}) \mathrm{J}$ recombination and thus to produce viable lymphocytes, a preliminary process to Ig class switching. Multiple myeloma, in contrast, is characterised by aberrant class switch recombination; therefore, A3V and T9I variants may have a different impact upon each of these rearrangement mechanisms. Alternatively, it may be proposed that LIG4 A3V and T9I in the absence of mutation such as $\mathrm{R} 278 \mathrm{H}$ confer a reduced risk of chromosomal instability and subsequent malignancy as observed for multiple myeloma in this study. However, when combined with other genetic defects, $\mathrm{A} 3 \mathrm{~V}$ and T9I enhance the effect of that mutation upon DNA ligase IV, producing a more severe clinical phenotype, such as that observed for patient $411 \mathrm{BR}$.

It has been proposed that the non-catalytic regions of human DNA ligases contain unique regions that determine the protein-protein interactions, and therefore the differential cellular functions of these enzymes. ${ }^{31}$ Ligase IV forms a complex with XRCC4 via the non-catalytic C-terminus, which contains tandem BRCT motifs between which XRCC4 binds. XRCC4 is essential for ligase IV protein stabilisation and activity, stimulating adenylation of ligase IV, the initial step in ligation. ${ }^{32}{ }^{33}$ Recent structural analysis of XRCC4 suggests the protein forms a dumbbell-like tetramer, allowing multivalent ligase IV and DNA binding. ${ }^{34}$ Although the N-terminus sequence of DNA ligase IV containing A3V and T9I is not highly conserved, this region has been shown to be essential for ligase IV activity. ${ }^{19}$ It has been shown that ligase IV stability is not affected by the A3V or T9I polymorphisms, but they are predicted to increase the hydrophobicity of the region. More detailed analysis using structural modelling programmes predicts an impact on the protein's tertiary structure (P A Jeggo, unpublished data). It may be proposed that the protective effect of the LIG4 variants seen in this study results from the A3V and T9I substitutions altering the protein-protein interactions of DNA ligase IV with components of the NHEJ pathway, such as XRCC4, or with other ligation processes in which the enzyme is involved.

\section{ACKNOWLEDGEMENTS}

The authors would like to thank Dr A Childs and the consultants and staff involved in the UK Leukaemia Research Fund and Medical Research Council studies. PLR, SR, and GJM are funded by the Leukaemia Research Fund of Great Britain. The PAJ laboratory is funded by a Medical Research Council Programme Grant, with MOD supported by the Leukaemia Research Fund.

\section{Authors' affiliations}

P L Roddam, S Rollinson, A Jack, G J Morgan, Academic Unit of Haematology and Oncology, University of Leeds, Algernon Firth Building, Leeds, West Yorkshire LS2 9JT, UK

M O'Driscoll, P A Jeggo, Genome Damage and Stability Unit, University of Sussex, Falmer, Brighton, East Sussex BNI 9RR, UK

\section{REFERENCES}

1 Vanasse GJ, Concannon P, Willerford DM. Regulated genomic instability and neoplasia in the lymphoid lineage. Blood 1999:94:3997-4010.

2 Kanaar R, Hoeijmakers JHI, van Gent DC. Molecular mechanisms of DNA double-strand break repair. Trends Cell Biol 1998;8:483-9.

3 van Gent DC, Hoeijmakers JHI, Kanaar R. Chromosomal stability and the DNA double-stranded break connection. Nat Genet $2001 ; 2: 196-206$
4 Frank KM, Sekiguchi JAM, Seidl KJ, Swat W, Rathburn GA, Cheng HL, Davidson L, Kangaloo L, Alt FW. Late embryonic lethality and impaired $\mathrm{V}(\mathrm{D}) \mathrm{J}$ recombination in mice lacking DNA ligase IV. Nature 1998:396:173-7

5 Taccioli GE, Amatucci AG, Beamish HJ, Gell D, Xiang XH, Torres Arzayus MI, Priestley A, Jackson SP, Rothstein AM, Jeggo PA, Herrera VLM. Targeted disruption of the catalytic subunit of the DNA-PK gene in mice confers severe combined immunodeficiency and radiosensitivity. Immunity 1998:9:355-66.

6 Manis JP, Gu Y, Lansford R, Sonoda E, Ferrini R, Davidson L, Rajewsky $\mathrm{K}$, Alt Fw. Ku70 is required for late B cell development and immunoglobulin heavy chain class switching. J Exp Med 1998; 187:2081-9.

7 Grawunder U, Zimmer D, Fugmann S, Schwarz K, Lieber MR. DNA ligase IV is essential for V(D)J recombination and DNA double-strand break repair in human precursor lymphocytes. Mol Cell 1998;2:477-84

8 Bemark M, Sale JE, Kim HJ, Berek C, Cosgrove RA, Neuberger MS. Somatic hypermutation in the absence of DNA-dependent protein kinase catalytic subunit (DNA-PK ${ }_{\mathrm{cs}}$ ) or recombination-activating gene (RAG-1) activity. J Exp Med 2000;192:1509-14.

9 Singleton BK, Priestley A, Steingrimsdottir H, Gell D, Blunt T, Jackson SP, Lehmann AR, Jeggo PA. Molecular and biochemical characterisation of xrs mutants defective in Ku80. Mol Cell Biol 1997;17:1264-73.

10 Grawunder U, Zimmer D, Kulesza P, Lieber MR. Requirement for an interaction of XRCC4 with DNA ligase IV for wild-type V(D)J recombination and DNA double-strand break repair in vivo. $J$ Biol Chem 1998;273:24708-14.

11 Gao, Y, Ferguson DO, Xie W, Manis JP, Sekiguchi JA, Frank KM Chaudhuri J, Horner J, DePinho RA, Alt FW. Interplay of p53 and DNA-repair protein XRCC4 in tumourgenesis, genomic stability and development. Nature 2000;404:897-900

12 Ferguson DO, Sekiguchi JAM, Chang S, Frank KM, Gao Y, DePinho RA, Alt FW. The nonhomologous end-joining pathway of DNA repair is required for genomic stability and the suppression of translocations. Proc Natl Acad Sci USA 2000;97:6630-3.

13 Sekiguchi J, Ferguson DO, Chen HT, Yang EM, Earle J, Frank K, Whitlow S, Gu Y, Xu Y, Nussenzweig A, Alt FW. Genetic interactions between ATM and the nonhomologous end-joining factors in genome stability and development. Proc Natl Acad Sci USA 2001;98:3243-8.

14 Roth DB, Gellert M. New guardians of the genome. Nature 2000;404:823-5

15 Difilippantonio MJ, Zhu J, Chen HT, Meffre E, Nussenzweig MC, Max $\mathrm{EE}$, Reid T, Nussenzweig A. DNA repair protein Ku80 suppresses chromosomal aberrations and malignant transformation. Nature 2000;404:510-14.

16 Gennery AR, Cant AJ, Jeggo PA. Immunodeficiency associated with DNA repair defects. Clin Exp Immunol 2000;121:1-7.

17 Riballo E, Critchlow SE, Teo SH, Doherty AJ, Priestley A, Broughton B, Kysela B, Beamish H, Plowman N, Arlett CF, Lehmann AR, Jackson SP, Jeggo PA. Identification of a defect in DNA ligase IV in a radiosensitive leukaemia patient. Curr Biol 1999;9:699-702

18 O’Driscoll M, Cerosaletti KM, Girard P-M, Dai Y, Stumm M, Kysela B, Hirsch B, Gennery A, Palmer SE, Seidel J, Gatti RA, Varon R, Oettinger MA, Neitzel H, Jeggo PA, Concannon P. DNA ligase IV mutations identified in patients exhibiting development delay and immunodeficiency. Mol Cell 2001;8:1175-85.

19 Grawunder U, Zimmer D, Lieber MR. DNA ligase IV binds to XRCC4 via a motif located between rather than within its BRCT domains. Curr Biol 1998:8:873-6.

20 Harris NL, Jaffe ES, Diebold J, Flandrin G, Muller-Hermelink HK, Vardiman J, Lister TA, Bloomfield CD. The World Health Organization classification of neoplastic diseases of the hematopoietic and lymphoid tissues. Ann Oncol 1999;10:1419-143.

21 Kuppers R, Dalla-Favera R. Mechanisms of chromosomal translocations in B cell lymphomas. Oncogene $2001 ; 20: 5580-94$.

22 Roddam PL, Rollinson S, Kane E, Roman E, Moorman A, Morgan GJ. Risk of adult acute leukaemia associated with polymorphism at the cytochrome P450 2D6 and 2C19 loci. Pharmacogenetics 2000; 10:605-15

23 Vaandrager JW, Schuuring E, Philiippo K, Kluin PM. V(D)J recombinase-mediated transposition of the $\mathrm{BCL} 2$ gene to the IGH locus in follicular lymphoma. Blood 2000;96: 1947-52.

24 Grawunder U, Harfst E. How to make ends meet in V(D)J recombination. Curr Opin Immunol 2001;13:186-94

25 Papavasiliou $F$, Casellas R, Suh H, Qin XF, Besmer E, Pelanda R, Nemazee D, Rajewsky K, Nussenweig MC. V(D)J recombination in mature $B$ cells: a mechanism for altering antibody responses. Science 1997; 278:298-301

26 Storb U, Shen HM, Michael N, Kim N. Somatic hypermutation of immunoglobulin and non-immunoglobulin genes. Philos Trans $R$ Soc $B$ 2001;356:13-19.

27 Fenton JAL, Vaandrager JW, Aarts WM, Bende R, Heering K, van Dijk $M$, Morgan GJ, van Noesel CJM, Schurring E, Kluin PM. Follicular lymphoma with a novel $t(14 ; 18)$ breakpoint involving the immunoglobulin heavy chain switch mu region indicates an origin from germinal centre $B$ cells. Blood 2002;99:716-18.

28 Fenton JAL, Pratt G, Rawstron AC, Morgan GJ. Isotype class switching and the pathogenesis of multiple myeloma. Hematol Oncol 2002;19:1-12 
29 Ehrenstein MR, Rada C, Jones AM, Milstein C, Neuberger MS. Switch junction sequences in PMS2-deficient mice reveal a microhomology-mediated mechanism of Ig class switch recombination. Proc Natl Acad Sci USA 2001;98:14553-8.

30 Kinoshita K, Honjo T. Linking class-switch recombination with somatic hypermutation. Nat Rev Mol Cell Biol 2001;2:493-503.

31 Chen L, Trujillo K, Sung P, Tomkinson AE. Interactions of the DNA ligase IV-XRCC 4 complex with DNA ends and the DNA-dependent protein kinase. J Biol Chem 2000;275:26196-205.
32 Bryans M Valenzano MC, Stamato TD. Absence of DNA ligase IV protein in XR-1 cells: evidence for stabilization by XRCC4. Mutat Res 1999;433:53-8.

33 Modesti M, Hesse JE, Gellert M. DNA binding of Xrrc4 protein is associated with $V(D) J$ recombination but not with stimulation of DNA ligase IV activity. EMBO J 1999;18:2008-18.

34 Junop MS, Modesti M, Guarne A, Ghirlando R, Gellert M, Yang W. Crystal structure of the Xrcc4 DNA repair protein and implications for end joining. EMBO J 2000;19:5962-70.

\section{$\mathrm{ECHO}$}

\section{Unlinked genes influence severity of FAP within families}

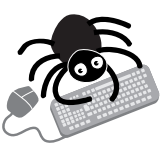

Please visit the Journal of

Medical

Genetics

website [www

jmedgenet.com]

for link to this

full article. study of how familial adenomatous polyposis (FAP) varies within families supports the hypothesis
that modifier genes affect the severity of the disease. This in turn may provide new insights into
tumour formation in the gut. Severity of FAP was significantly members with severe disease, associated with a high polyp count, had mutations clustering in the

Polyp counts showed a higher, significant, correlation for close relatives within a family than more distant relatives. The correlation coefficient, corrected for germline APC mutation, in sibling pairs was 0.42 for parent-sibling pairs was 0.29 , and for more distant relatives was even weaker. Segregation analysis showed that a mixed model of inheritance not linked to the APC gene best fitted the data..

One hundred and sixty six patients from 55 families were studied. They had classic FAP and had had a prophylactic colectomy; 128 had known APC gene mutation. Counts of polyps in the colectomy samples were grouped by $A P C$ mutation indicating the genotype-phenotype relation, and correlation coefficients were calculated to assess variation within families independently of $A P C$ mutation, on the premise that closer relatives have more shared modifier genes.

FAP shows characteristic phenotypic variation, only some of which is due to APC gene mutations. The rest might be explained by a modifier gene or genes, as occurs in a mouse model.

A Gut 2002;51:420-423. 